\title{
Shwachman syndrome associated with de novo reciprocal translocation $\mathrm{t}(6 ; 12)(\mathrm{q} 16.2 ; \mathrm{q} 21.2)$
}

\author{
M Masuno, K Imaizumi, G Nishimura, M Nakamura, I Saito, K Akagi, Y Kuroki
}

\begin{abstract}
We describe a de novo apparently balanced reciprocal translocation $t(6 ; 12)(q 16.2$; q21.2) in an 18 month old girl with Shwachman syndrome, characterised by exocrine pancreatic insufficiency and bone marrow dysfunction. The cause of this syndrome is unknown, although autosomal recessive inheritance has been proposed. The translocation breakpoints in the present patient may be candidate regions for a gene responsible for Shwachman syndrome.
\end{abstract}

(f Med Genet 1995;32:894-895)

Shwachman syndrome (MIM *260400) is a rare genetic disorder characterised by exocrine pancreatic insufficiency, growth retardation, bone marrow dysfunction resulting in neutropenia, and metaphyseal chondrodysplasia. ${ }^{1}$ In some instances, psychomotor development is impaired. ${ }^{23}$ At the present time, the cause of this syndrome is unknown, although autosomal recessive inheritance has been suggested. ${ }^{2}$

A similar constellation of the digestive abnormalities, haematological changes, and metaphyseal chondrodysplasia is seen in cartilagehair hypoplasia (MIM *250250), which has been shown to be linked to $9 \mathrm{p} 21-\mathrm{p} 13 .{ }^{4} \mathrm{~A}$ gene for Fanconi anaemia (MIM *227650) characterised by skeletal abnormalities and progressive bone marrow failure has been cloned, with no significant homology to any of the database sequences. ${ }^{5}$ It has been localised to 9q22.3. ${ }^{6}$

Here we report a patient with Shwachman syndrome associated with a de novo reciprocal $t(6 ; 12)(q 16.2 ; q 21.2)$. The possibility that one of the chromosome breakpoints includes the critical region for Shwachman syndrome is discussed.

Division of Infection Immunology, and Rheumatology, Kanagawa Children's Medical Centre, 2-138-4 Mutsukawa, Minami-ku, Yokohama 232, Japan I Saito

K Akagi

Department of Radiology, Dokkyo University School of Medicine, Mibu, Tochigi 321-02, Japan

G Nishimura

Correspondence to: Dr Masuno.

Received 30 May 1995 Revised version accepted for publication 3 July 1995 complicated by pneumonia. She has had chronic diarrhoea with recurrent steatorrhoea since 2 months of age.
She was first evaluated by us at the age of 3 months because of failure to thrive and liver dysfunction was found at that time. She lifted her head at the age of 4 months. At 7 months, hepatosplenomegaly was noted. She was able to sit up unaided at 9 months. At 10 months, she was admitted to our hospital for clinical investigation. Her weight was $5882 \mathrm{~g}(-2.9$ $\mathrm{SD})$, length $65.0 \mathrm{~cm}(-2.5 \mathrm{SD})$, and $\mathrm{OFC}$ $40.5 \mathrm{~cm}(-2.6 \mathrm{SD})$. Her muscle tone was normal. She was found to have a haemoglobin (Hb) level of $11.4 \mathrm{~g} / \mathrm{dl}$, a platelet count of $28.7 \times 10^{4} / \mu \mathrm{l}$, and a range of white cell count of $4800-11400 / \mathrm{mm}^{3}$ (neutrophils 184-2052/ $\mathrm{mm}^{3}$ ), indicating cyclic neutropenia. $\mathrm{Hb}$ electrophoresis showed a mild increase in the proportion of $\mathrm{Hb} \mathrm{F}(4 \cdot 2 \%)$. A bone marrow examination showed a slightly hypocellular marrow without maturation arrest. The range of liver transaminases was increased (AST 75-228 IU/l; ALT 78-232 IU/l). A systemic skeletal survey showed a mildly hypoplastic thoracic cage, slight expansion of the anterior ends of the ribs, and metaphyseal dysplasia of the proximal femur. CT scan of the abdomen showed a pancreas that was totally replaced by fatty tissue (HU -91·4). Both liver and spleen were moderately enlarged with a normal density. In addition magnetic resonance imaging of the abdomen was performed. The pancreas had a very high signal intensity similar to that of fat on $\mathrm{Tl}$ weighted imaging and an intermediate signal intensity on T2 weighted imaging, indicating lipomatosis of the pancreas. ${ }^{7}$ Examination of the stool showed markedly increased fat. Duodenal intubation showed decreased or absent amylase activity in the fluid obtained both before and after secretin administration. Serum amylase was decreased to $22 \mathrm{IU} / 1$ (8.1:1 ratio of non-pancreatic to pancreatic amylase). The glucose tolerance test was normal. Immunological tests were normal including serum IgG, IgA, IgM, C3, and C4 concentrations, lymphocyte responses to phytohaemagglutinin (PHA) and concanavalin A, and relative counts of $T$ subset lymphocytes. Thyroid function, alpha-1 antitrypsin, serum amino acids, lactate and pyruvate, ammonia, and blood gas analysis were normal. The ophthalmological findings and cardiac evaluation were unremarkable. Based on the above findings, a diagnosis of Shwachman syndrome was made. She was managed with pancreatic extracts for her malabsorption.

She could walk without support at 15 months. At 18 months, she was $74.0 \mathrm{~cm}(-1.9$ SD) in height, weighed $8605 \mathrm{~g}(-1.3 \mathrm{SD})$, and had an OFC of $43.5 \mathrm{~cm}(-2 \cdot 1 \mathrm{SD})$. She had frequent febrile episodes, which were successfully treated with antibiotics. 


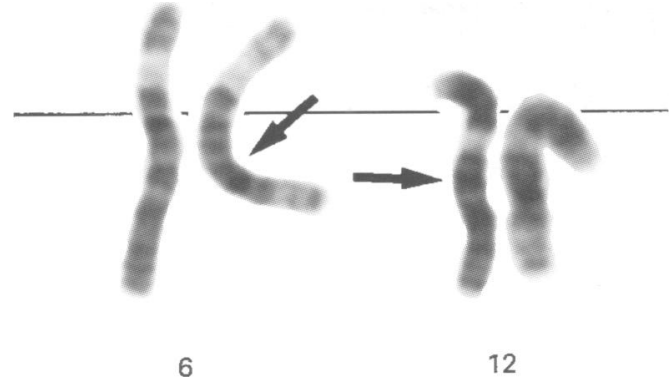

Partial $G$ banded karyotype of the proband. Arrows show the breakpoints of $6 q 16.2$ and 12q21.2.

\section{CYTOGENETIC FINDINGS}

Chromosome analysis was made from peripheral lymphocyte culture for 72 hours with PHA stimulation. The proband's karyotype by high resolution GTG banding was $46, \mathrm{XX}, \mathrm{t}(6$; 12)(q16.2; q21.2) (figure). Although it is less likely, an alternative possibility of $46, \mathrm{XX}, \mathrm{t}(6$; 12) $(\mathrm{q} 15 ; \mathrm{q} 15)$ is not excluded. This finding was confirmed by bone marrow analysis. The chromosomes of both parents were normal. At the age of 11 months, spontaneous chromosome breakage was not observed in 100 Giemsa stained metaphases of the proband in agreement with the findings of Koiffmann et $a l,{ }^{8}$ but in contrast to the report of Tada et al. ${ }^{9}$

EBV transformed lymphoblastoid cell lines from the present patient (KCMC-530) and her parents (KCMC-614 and KCMC-632) are available from Dr M Masuno.

\section{Discussion}

This report concerns an 18 month old Japanese girl with typical Shwachman syndrome and a de novo apparently balanced reciprocal translocation $\mathrm{t}(6 ; 12)(\mathrm{q} 16.2 ; \mathrm{q} 21.2)$. The cause and gene locus responsible for this syndrome are unknown but autosomal recessive inheritance has been suggested. ${ }^{2}$ Physical gene disruption with consequent loss of function at the breakpoints of a chromosomal translocation may lead to functional homozygosity of a recessive gene located at one of the sites of the respective translocation chromosomes. ${ }^{10}$ Thus, the translocation breakpoints $6 \mathrm{q} 16.2$ or $12 \mathrm{q} 21.2$ in the present patient may indicate a candidate region for Shwachman syndrome.

Aggett et $a l^{2}$ hypothesised that the basic defect in Shwachman syndrome is attributable to abnormal cellular secretion owing to malfunction of the microtubules and microfilaments. Interestingly, an alpha tubulin gene (TUBAL1) has been assigned to chromosome $12,{ }^{11}$ which is one of the chromosomes involved in the translocation breakpoints in our patient. Confirmation of the precise chromosome localisation of this gene may provide insight into the molecular defects of Shwachman syndrome.
Although the translocation in this patient appears to be balanced, the possibility that subtle chromosome material is deleted from one or both the chromosomes involved is not excluded. The present patient is a sporadic case with typical Shwachman syndrome except for incomplete cleft lip. Cleft lip and palate was described in a patient with interstitial deletion of 12q13.3-q21.1. ${ }^{12}$ Cutaneous syndactyly and hypertelorism are rarely found in Shwachman syndrome, ${ }^{2}$ but are observed in patients with an interstitial deletion or apparently balanced translocations involving the breakpoints of 12q15-q21.2. ${ }^{13-15}$ Therefore, the present patient may have a submicroscopic deletion at 12q21.2 and the locus of the gene responsible for Shwachman syndrome seems to be at $12 \mathrm{q} 21.2$ rather than $6 \mathrm{q} 16.2$, if the translocation results in a gene mutation leading to this syndrome.

Careful cytogenetic studies in other patients with Shwachman syndrome will be of great interest to establish whether the present association is fortuitous or whether it is an indication for the localisation of this autosomal recessive syndrome at $6 \mathrm{q} 16.2$ or $12 \mathrm{q} 21.2$.

We are grateful to A Omiya and I Nanba for their technical assistance in the cytogenetic study. This study was supported in part by a Research Grant $(5 \mathrm{~A}-5)$ for Nervous and Menta Disorders and a grant for research on mental retardation from the Ministry of Health and Welfare, Japan.

1 Shwachman H, Diamond LK, Oski FA, Khaw KT. The syndrome of pancreatic insufficiency and bone marrow dysfunction. $\mathcal{F}$ Pediatr 1964;65:645-63.

2 Aggett PJ, Cavanagh NPC, Matthew DJ, Pincott JR, Sutcliffe J, Harries JT. Shwachman's syndrome: a review of 21 cases. Arch Dis Child 1980;55:331-47.

3 Kent A, Murphy GH, Milla P. Psychological characteristics of children with Shwachman syndrome. Arch Dis Child 1990;65:1349-52.

4 Sulisalo T, Francomano CA, Sistonen P, et al. High-resolution genetic mapping of the cartilage-hair hypoplasia $(\mathrm{CHH})$ gene in Amish and Finnish families. Genomics 1994;20:347-53.

5 Strathdee CA, Gavish H, Shannon WR, Buchwald M. Cloning of cDNAs for Fanconi's anaemia by functional complementation. Nature 1992;356:763-7.

6 Strathdee CA, Duncan AMV, Buchwald M. Evidence for at least four Fanconi anaemia genes including FACC on chromosome 9. Nature Genet 1992;1:196-8.

7 Bom EP, van der Sande FM, Tjon A Tham RTO, Hillen HFP. Shwachman syndrome: CT and MR diagnosis. $\mathscr{f}$ Comput Assist Tomogr 1993;17:474-6.

8 Koiffmann CP, Gonzalez $\mathrm{CH}$, Souza $\mathrm{DH}$, Romani EG, Kim CA, Wajntal A. Is Shwachman syndrome (McKusick 26040) a chromosome breakage syndrome? Hum Gene 1991;87:106-7.

9 Tada $\mathrm{H}, \mathrm{Ri} \mathrm{T}$, Yoshida $\mathrm{H}$, et al. A case of Shwachman syndrome with increased spontaneous chromosome breakage. Hum Genet 1987;77:289-91.

10 Edwards $\mathrm{JH}$. Chromosomal abnormalities in Mendelian disorders. Lancet 1982;ii:322-323.

11 Gatti RA, Shaked R, Wei S, Mohandas TK, Salser W. Biallelic DNA polymorphism of an alpha-tubulin gene family member on chromosome 12 (TUBA/MspI/2.2; $2.0 \mathrm{~kb}$ ). Nucleic Acids Res 1987;15:8119.

12 Meinecke P, Meinecke R. Multiple malformation syndrome including cleft lip and palate and cardiac abnormalities including cleft lip and palate and cardiac abnormalities
due to an interstitial deletion of chromosome 12q. $7 \mathrm{Med}$ due to an interstitial
Genet $1987 ; 24: 187$.

13 Watson MS, McAllister-Barton L, Mahoney MJ, Breg WR. Deletion (12)(q15q21.2). F Med Genet 1989;26:343-4.

14 Hustinx TWJ, Gabreëls FJM, Rutten FJ, et al. A mentally retarded child with a translocation involving chromosomes 12 and 19. F Med Genet 1975;12:207-10.

15 Coco R, Penchaszadeh VB. Cytogenetic findings in 200 children with mental retardation and multiple congenital anomalies of unknown cause. Am $\mathcal{F}$ Med Genet 1982;12 155-73. 